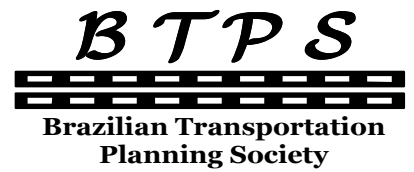

Journal of Transport Literature

Vol. 7, n. 3, pp. 34-58, Sep. 2013

Research Directory

JTL|RELIT

www.transport-literature.org ISSN 2238-1031

\title{
Bus route evaluation using a two-stage hybrid model of Fuzzy AHP and TOPSIS
}

[Avaliação de linhas de ônibus com uso de um modelo híbrido de dois estágios com Fuzzy AHP e TOPSIS]

\author{
Ali Soltani*, Ebrahim Zargari Marandi, Yousef Esmaili Ivaki \\ Shiraz University, Shiraz, Iran
}

Submitted 17 Jul 2012; received in revised form 15 Sep 2012; accepted 23 Sep 2012

\begin{abstract}
Public transportation users are constantly in search of regular service, fair cost, high safety, and physical and psychological comfort. Creating a system for bus route evaluation (BRE) can be considered to be among the basic requirements for public transportation management in cities. The need for a logical and scientific tool to support the decisions made by the policy makers of public transportation for the purpose of a higher quality of the services, specifically in a developing metropolitan such as Shiraz, Iran, proves the importance of such a system. In this study, firs, six routes among the 71 bus routes of metropolitan Shiraz were chosen. Subsequently, 16 criteria based on the theoretical literature and the data collected in a survey conducted by the Shiraz Public Bus Organization (SPBO) were produced. Then by using a two-stage multiple-criteria decision making (MCDM) model containing hierarchical Fuzzy Analytical Hierarchal Process (Fuzzy AHP) and TOPSIS methods the data was analyzed and the existing situation of the selected bus routes was evaluated. This study and the presented evaluation framework for the analysis of the current situation along with the comparison of the bus routes can help the managers and policy makers of bus transportation on their way to improving the services, developing the routes, merging the routes, and creating new routes.
\end{abstract}

Key words: evaluation, bus routes, Fuzzy AHP, TOPSIS, Shiraz.

\section{Resumo}

Usuários de transporte público estão constantemente em busca de regularidade do serviço, preço justo, segurança e conforto físico e psicológico. Criar um sistema de avaliação de linhas de ônibus pode ser considerado dentre os requisitos básicos para a gestão de transporte público nas cidades. A necessidade de uma ferramenta lógica e científica para apoiar as decisões tomadas pelos formuladores de políticas de transporte público com o objetivo de uma maior qualidade dos serviços, especificamente em uma área metropolitana em desenvolvimento como Shiraz, Irã, comprova a importância de tal sistema. Neste estudo, primeiramente, seis rotas entre as 71 linhas de ônibus da região metropolitana de Shiraz foram escolhidos. Posteriormente, 16 critérios com base na literatura teórica e os dados coletados em uma pesquisa realizada pela Organização de ônibus Públicos de Shiraz (SPBO) foram produzidos. Em seguida, usando um modelo de dois estágios multi-critério de tomada de decisão (MCDM) contendo um Processo Hierárquico Analítico Difuso (Fuzzy AHP) e métodos TOPSIS, os dados foram analisados e a situação atual das linhas de ônibus selecionadas foi avaliada. Este estudo e o arcabouço de avaliação apresentado para a análise da situação atual, juntamente com a comparação das linhas de ônibus, podem ajudar os gestores e formuladores de políticas de transporte de ônibus em iniciativas para a melhoria dos serviços, o desenvolvimento, fusão e criação de novas linhas.

Palavras-Chave: avaliação, linhas de ônibus, Fuzzy AHP, TOPSIS, Shiraz.

*Email: ali_soltani54@yahoo.com.

\section{Recommended Citation}

Soltani, A., Marandi, E. Z and Ivaki, Y. E. (2013) Bus route evaluation using a two-stage hybrid model of fuzzy AHP and TOPSIS. Journal of Transport Literature, vol. 7, n. 3, pp. 34-58.

- JTL/RELIT is a fully electronic, peer-reviewed, open access, international journal focused on emerging transport markets and published by BPTS - Brazilian Transport Planning Society. Website www.transport-literature.org. ISSN 2238-1031. 


\section{Introduction}

This paper seeks to provide bus industry managers and planners with a logical and scientific tool to support the decisions made in hope of achieving a higher quality of the services. One of the most important duties of managers and policy makers in every field is the issue of evaluation of current situation. A proper evaluation can simultaneously enlighten the situations regarding the operational conditions, current problems, and the existing potentials for development and can also inspect the existing as guidelines for future actions and improvements. Nowadays, public transportation services are considered to be one of the main modes of travel for the citizens of metropolitan areas. The planning and managing of bus routes are of important issues for the officials of urban transportation.

Public bus passengers are in search of regular services, suitable costs, high safety, and comfort (Zhou et al., 2011) and this leads to a constant effort to improve the quality of bus transportation permanently in order to encourage the public to use this mode of transport. Optimizing the operational costs for the providers of bus services is also among the goals of public transportation planners. One can say that the purpose is to minimize the total costs which include access time, waiting time, time spent on bus, expenses for passengers, and operational costs for bus, together with the costs paid for trip quality and comfort for passengers (Wirasinghe and Vandebona, 2011).

In this way, providing planners and managers with an appropriate framework for the purpose of bus route evaluation is a necessity. One of the basic problems the policy makers and executives in this area face with is receiving too much information from isolated sources which is completely devoid of practical guidance for service improvement (Sheth et al., 2007: 453). Therefore, in many cases, bus route planning is based on practical experience which can lead to problems such as extra expenses, low operational speed, insufficient area coverage, and inconvenient transport (Huang et al. 2007: 419).

A number of studies on Public Transit Network Evaluation (PTNE) have been conducted within past few years around the world. However, the number of studies conducted on bus route evaluation is only some. One of the primary studies in this field was the Project of 
Formulating the Standards of Bus Routes conducted by The Federal Transit Administration in United States. This project presented 44 criteria in five categories of route design, time schedule, economy and productivity, services, and safety and comfort (The Federal Transit Administration, 1995). Among the scientific studies conducted in this area, one can mention the ones by Huang, Shen, and Guan (Huang et al. 2007), Sheth, Triantis, and Theodorovich (Sheth et al, 2007), Chen, Yu, Zhuang, and Gu (Chen et al,2009), Eichler and Daganzo (Eichler \& Daganzo, 2006), Wirasinghe \& Vandebona (Wirasinghe \& Vandebona, 2011), and Lao \& Liu, 2009 (Lao \& Liu, 2009). Considering the fact that bus route evaluation is a very complicated issue and depends on a high number of criteria, one of the best methods of analysis for this issue is using multi-criteria Analysis models.

The main contribution of this paper to the existing literature is apparent. The paper gives an attempt to provide bus managers and planners with a comprehensive and credible evaluation system in which a wide array of objective measures exist. The well-known models of TOPSIS and Fuzzy AHP are rarely applied for bus system planning research. They have been mostly in use for location -allocation of public services. A limited number of studies can be found in which such hybrid model is applied (e.g. Huang et al., 2007, Lao and Liu, 2009, Wirasinghe and Vandebona, 2011). Comparing to existing literature, the number of variables is higher, furthermore, the weighting system is not only based on expert opinions but also enjoys from a set of objective measures applied on real data.

The paper is organized in five parts: first, the problem for evaluation is organized and subsequent to the formation of a number of measurable criteria, the routes are evaluated and ranked by using a Multi-Criteria Decision Making (MCDM) model. second, the criteria for bus route evaluation are discussed. In the third section, Fuzzy Analytic Hierarchy Process (Fuzzy AHP) and Technique for Order Performance by Similarity to Ideal Solution (TOPSIS) are explained. third, the bus routes in the city of Shiraz in accordance with the abovementioned model are evaluated using the appropriate criteria (based on the existing data). Consequently, in the final section, conclusions are drawn and suggestions for further research are put forward. 


\section{The Criteria for Bus Route Evaluation (BRE)}

Not only the connection between the routes is a subject of BRE process, but "the BRE should assess objectively the operating characteristics and effects of individual routes" (Huang et al, 2007: 419). For this kind of evaluation, the basic criteria must be designed in some categories and then the sub-criteria needed and the indicators according to assessment objectives are to be put forward. In this study, the criteria are analyzed in the four categories of Route Design (RD), Schedule Design (SD), Economic and Productivity (EP), Passenger Comfort and Safety (PC). In addition to the sub-criteria, more useful criteria may exist which are excluded from this study due to the similarities between the routes or lack of data.

\subsection{Bus Route Design}

This criterion shows the suitability for presenting services to passengers and includes five sub-criteria. In fact, the sub-criteria related to route design are in relation with the basic form and design of the transportation network and factors like the location of services, the typology of the routes, and the users' access to transport services (The Federal Transit Administration, 1995).

\subsubsection{Population Density}

This sub-criterion, in fact, shows the potential of a bus stop in attracting passengers. The higher the population density, the higher the potential volume of passengers is (Sheth et al., 2007). The proper distance for determining the area for population density is 400 meters which can be considered as the proper distance for gaining access to the bus route on foot (Tomazinis, 1975).

\subsubsection{Employment Density}

This sub-criterion is considered to be the factor for trip attraction in nearby areas of bus routes and is one of frequently used measures for bus route design evaluation (The Federal Transit Administration, 1995). The methodology for measuring this sub-criterion is the same as that of population density and they both have a positive potential effect on the evaluation (the higher the better). 


\subsubsection{Route Directness}

This parameter, which is also known as the Non-Linear Factor of the route in some studies (Huang et al., 2007), in fact, shows the degree to which the bus route deviates from the shortest path joining the beginning to the end of the route. In cases where making use of network analysis for the streets is not possible, the direct distance between the beginning and the end can be used as the shortest path instead.

$$
R D F=\frac{L}{L s}
$$

Here, $\mathrm{L}$ is the current length of the route and Ls is the shortest path acquired from Network Analysis in ArcGIS 9.3. The closer to 1 this indicator is, the better.

\subsubsection{Route Overlapping}

This criterion is used in order to investigate the unnecessary overlap of the routes and the lower this overlap is, the better it is in the evaluation. The area considered for the overlap is 20 meters. The index for measuring this criterion is calculated as follows (Huang et al, 2007).

$$
R O=\frac{\sum L i}{L}
$$

Where $\mathrm{L}_{\mathrm{i}}$ is the number of kilometers in which the route $i$ overlaps or parallels with route under evaluation.

\subsubsection{Network Connectivity}

This sub-criterion gives the passengers more degree of freedom in changing their route or shifting their mode of travel and, therefore, affects their satisfaction (Sheth et al., 2007). In some studies (Huang et al, 2007), this criterion is regarded as Correlation Degree (with public transit hub) and the less distant the stops of the route under evaluation are from other bus stops (of other routes) or the stops of other public transportation vehicles like city trains, the better and stronger this correlation is. Other criteria such as Bus Stop Spacing, Service Equity, the proper design of the stops, and adjacency with non-residential areas can also be used but due to the similarities between the routes or insufficient data, they are excluded. 


\subsection{Scheduling Criteria}

This category of criteria is in relation with regular scheduling and the suitability of the schedule in line with how the bus seats are occupied through the route (The Federal Transit Administration, 1995).

\subsubsection{Headway Evenness}

This criterion shows the amount of delay for the arrival of the bus in the route stops. In principle, buses are to arrive in stops no sooner than one minute and no later than two minutes than the schedule (Huang et al., 2007). The index for measuring this criterion is the Standard Deviation of the time for moving in between the stops. A higher standard deviation is considered to be a negative factor (Chen et al., 2009).

\subsubsection{Dispatching Evenness}

The index for this criterion, like the previous one, is the standard deviation of time of departure from the initial point and the higher it is, the more irregularity in running the schedule it represents.

\subsubsection{Duration of Standee Time}

This criterion shows the desirability of the schedule in providing services in such a way that the lowest possible number of people remain standing in the bus. It's index is the ratio of the average time passengers spend standing in the bus to the total time of the trip from the beginning to the end (The Federal Transit Administration, 1995).

\subsubsection{Standee vs. No-Standee}

This criterion shows the average ratio of the people standing to the people sitting through the whole route. Similar to the previous criterion, a higher amount of this criterion is considered to be undesirable. 


\subsubsection{Non-Equilibrium Factor}

This criterion represents the equilibrium in maintaining the consistency of passenger flow in a given route during the hours services are presented. The index for this criterion is the standard deviation of passenger flow during service hours.

\subsection{Economic and Productivity Criteria}

These criteria show the level of efficiency and optimal performance under which bus routes function from an economic point of view.

\subsubsection{Kilometers Utilization Rate}

This criterion represents the ratio of the distance from the route in which passengers are transported to the total distance (Huang et al., 2007) and, in fact, shows the functional efficiency and optimal design of a given bus route.

\subsubsection{Passenger per Kilometer Criterion}

It represents the ratio of the passengers transported to the total number of kilometers covered. The higher this ratio is the higher efficiency of passenger transportation it represents. Due to the fact that ticket prices are constant for all bus routes in Shiraz, the Income per Kilometer for each route is completely dependent on this criterion and no other independent criterion for income is considered.

Other factors such as route costs, energy costs for the buses, maintenance costs, etc can also be of use but are excluded here. It should be noted, however, that in many countries, the use of bus services and its economical success are due to the policy of imposing parking costs which is enforced by the local authorities. Increasing service quality and improving the timing criteria are also of high influence on the economic efficiency of bus routes (Wall and McDonald, 2007). 


\subsection{Passenger Safety and Comfort}

Although the above-mentioned factors for the timing criteria have significant importance in gaining passenger satisfaction and the time spent in the bus stops is sometimes twice as important for the passengers than the time spent on the bus during the trip (Oort and Nes, 2003), the criteria for passenger safety and comfort have also of a significant role in raising a public trend for using buses and creating social justice.

\subsubsection{Operational Speed}

The index for calculating operational speed is the following equation:

$$
V=\frac{L}{t_{0}}
$$

where $\mathrm{L}$ is the total length of the route and $t_{0}$ is the time spent for covering the whole route from the initial point to the end, including the time spent in the stops.

Some other criteria for bus route evaluation applied in this study include:

- The number of students living within the 400-meter proximity of the stops (STU);

- The number of people aged 65 years and over living within the 400-meter proximity of the stops (OLD); and

- The number of disabled living within the 400-meter proximity of the stops (DSB).

Two last criteria have been used by Lao and Liu (2009). For the bus route evaluation in Shiraz, due to the fact that the buses have similar characteristics, the evaluations based on the characteristics of the buses (such as the kind of energy consumed, etc) are excluded. 


\section{Methodology}

The use of MCDM models for urban management and planning analysis goes back to several decades ago. For urban context, due to existence of several factors and alternatives ahead, the use of suitable MCDM models can help decision makers face complicated problems (Awasthi et al., 2011a; Awasthi et al., 2011b) and lead them to best choices based on the designated criteria (Yue, 2011). For the purposes of improving MCDM models, merging different methods to create an adhoc framework for analyzing problems, and inserting different judgments to the fuzzy environment, several pieces of research have been carried out in the past years. One of these blended frameworks is the use of a two-stage process by merging AHP and TOPSIS. Examples can be the studies conducted by Gumus (2009) and Dağdeviren et al. (2009). For the problem of bus route evaluation, it should be noted that for an appropriate and efficient evaluation to be carried out, decision makers are in need of analyzing a vast amount of data and considering multiple criteria when trying to make a decision (Ayag and Ozdemir, 2006; Mahmoodzadeh et al., 2007). However, one cannot perfectly judge which model is superior or lower than others. It can only be suggested that some techniques are more appropriate than others for decision making in some cases (Mergias et al., 2007; Opricovic and Tzeng, 2004).

For the present study, due to the existence of a low amount of data for the BRE indicators and a high number of alternatives (specifically when considering a higher number of bus routes is desired), first a Fuzzy AHP is used to determine the weight of the criteria and subcriteria for bus route evaluation in a hierarchical construction. In the second stage, the TOPSIS method is employed to evaluate the alternatives (bus routes), considering the weights obtained in the previous stage. The steps for using this hybrid model in the present study are shown in Figure 1. 


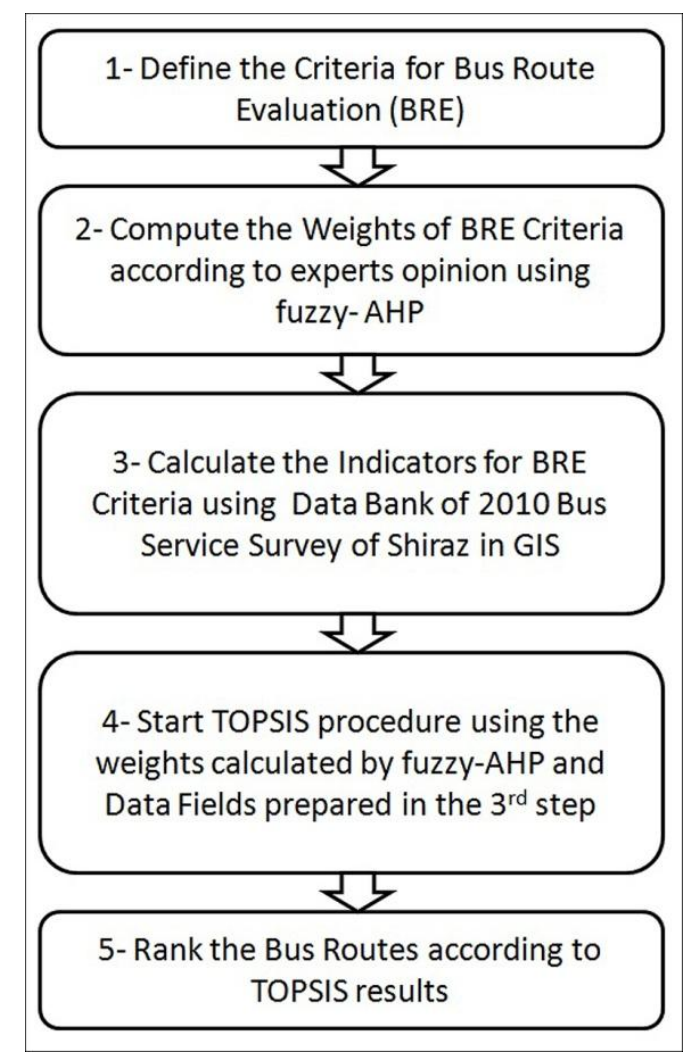

Fig. 1- The methodology of the study

\subsection{Fuzzy AHP Model}

The Fuzzy AHP model was first put forward by Thomas Saaty in the late 1970's for the purpose of determining the importance of a number of choices based on a multiple-criteria construction. Among the advantages of this model is the possibility for blending qualitative and quantitative data in a logical construction (Badri, 2001). The AHP model includes three main stages of determining the goal, formulating the hierarchical construction and determining the weight of the criteria, and determining the weight of the choices based on their situation in relation with the criteria mentioned above.

An important point which has been mentioned in this respect was that a suitable decision making model is expected to be tolerant against uncertainty and vagueness and this characteristic of uncertainty and vagueness is shared by many decision-making problems ( $\mathrm{Yu}$, 2002). The traditional AHP model, functions based on judgment and the selection of a 9 scale value for pair-wise comparison. However these crisp values cannot include the uncertainty existing in the expert's opinion (Gumus, 2009). Therefore, using the Fuzzy numbers for 
expressing uncertainty, as first put forward by Zadeh (1965), can improve the function of AHP significantly and make it more efficient (Lee et al.,2008). In this study, for Fuzzy judgments Triangular Fuzzy Numbers (TFN) are employed and the Defuzzification method is resulted from Reciprocal Matrixes and Centroid: Center of Area (CoA) method which is among the most precise methods of Defuzzification (Ross, 2004).

$$
\mu_{A(x)}= \begin{cases}\frac{x-l}{m-l}, & l \leq x \leq m \\ \frac{u-x}{u-m}, & m \leq x \leq u \\ 0 & \text { otherwise }\end{cases}
$$

The stages for the Fuzzy AHP are as follows:

a. Formulation of the Hierarchical Construction Based on the Goal, the Criteria, and the Choices

b. Formulation of the Reciprocal Matrix for giving weight to the criteria

$$
\tilde{A}=\left(\tilde{a}_{i j}\right)_{n \times n}=\left[\begin{array}{cccc}
(1,1,1) & \left(l_{12}, m_{12}, u_{12}\right) & \ldots & \left(l_{1 n}, m_{1 n}, u_{1 n}\right) \\
\left(l_{21}, m_{21}, u_{21}\right) & (1,1,1) & \ldots & \\
& \vdots & & \left(l_{2 n}, m_{2 n}, u_{2 n}\right) \\
\left(l_{n 1}, m_{n 1}, u_{n 1}\right) & \left(l_{n 2}, m_{n 2}, u_{n 2}\right) & \ldots & (1,1,1)
\end{array}\right]
$$

where $\tilde{a}_{i j}=\left(l_{i j}, m_{i j}, u_{i j}\right), \tilde{a}_{i j}^{-1}=\left(1 / u_{i j}, 1 / m_{i j}, 1 / l_{i j}\right)$, for $i, j=1,2, \ldots, n$ and $i \neq j$

c. Calculating the Fuzzy Weight of the Criteria

$$
\hat{S}_{i}=\frac{\sum_{j=1}^{n} \tilde{a}_{i j}}{\sum_{k=1}^{n} \sum_{j=1}^{n} \tilde{a}_{k j}}=\left[\frac{\sum_{j=1}^{n} l_{i j}}{\sum_{k=1}^{n} \sum_{j=1}^{n} u_{k j}}, \frac{\sum_{j=1}^{n} m_{i j}}{\sum_{k=1}^{n} \sum_{j=1}^{n} m_{k j}}, \frac{\sum_{j=1}^{n} u_{i j}}{\sum_{k=1}^{n} \sum_{j=1}^{n} l_{k j}}\right]
$$




\section{d. Defuzzification of the Results}

In previous works, many defuzzification methods have been used. A defuzzified value can be determined using the centre of area (CoA) method (Vahidnia et al., 2009). This method was suggested as the most accurate and also practical defuzzification technique. It is used in this research to determine the weight of each criterion or alternative. For those membership functions in which the precise determination of $X^{*}$ that does half the area of fuzzy numbers is hardly possible, the following equation is used to obtain the explicit number equivalent to the fuzzy number.

$$
X^{*}=\frac{\int \mu(x) x d x}{\int \mu(x) d x}
$$

However, for TFN with simple membership function, the following equation is suggested by the authors (Soltani \& Zargari, 2011).

If $\boldsymbol{X}=(1, \mathrm{~m}, \mathrm{u})$ and $(\mathrm{m}-\mathrm{l}) \geq(\mathrm{u}-\mathrm{m})$

$$
X^{*}=\sqrt{\frac{u \times m}{2}}
$$

Else

$$
X^{*}=u-\sqrt{\frac{u \times(u-m)}{2}}
$$

\section{e. Examining the Compatibility of the Judgments}

In order to examine the compatibility of the judgments (the existence of no inconsistency in the binary judgments) a ratio called the Consistency Ratio is used and for its value to be accepted, it must be below 0.1. In order to calculate the consistency ratio, first the Consistency Index must be calculated.

$$
C I=\frac{\left(\lambda_{\max }-n\right)}{(n-1)}
$$

and then CR is calculated: $C R=\frac{C I}{R I}$ 


\subsection{The TOPSIS Analysis}

This method was first suggested by Hwang and Yoon (1981) in accordance with the idea of ranking the choices based on their approximation to the ideal solution and their distance from the worst solution. The ideal choice is the one which minimizes the costs and maximizes the benefits and the negative choice is the one which maximizes the costs and minimizes the benefits (Wang \& Elhag, 2006). Among the advantages of this method are the facts that it possesses robust and vigorous logic, the mathematical calculations are really simple, and considers the best and the worst solutions while it has the ability to compare a high number of choices. The steps for the TOPSIS analysis are as follows:

\section{a. Formulation of the Decision Matrix}

In this step, a matrix is formed in which the rows are the choices and the columns are the criteria. In this matrix, $\mathrm{X}_{\mathrm{ij}}$ is the score of alternative $i$ in relation with criterion $j$.

\section{b. Normalizing the Decision Matrix}

Subsequent to forming the decision matrix with the existing data in the first step, the normalizing of the matrix is embarked on.

$$
n_{i j}=\frac{X_{i j}}{\sqrt{\sum_{i=1}^{m} X_{i j}^{2}}}
$$

where $i=1, \ldots, m ; j=1, \ldots, n$

\section{c. Forming the Normal Weighted Decision Making Matrix}

In this step, the weight of the criteria is applied based on the normal decision making matrix.

$$
V_{i j}=W_{j} \times n_{i j}
$$

where $i=1, \ldots, m ; j=1, \ldots, n$

Here, $W_{j}$ is the weight for the $\mathrm{j}^{\text {th }}$ criterion. The weights of the criteria must be normalized. 
d. Calculating the Positive Ideal Solution (PIS) and Negative Ideal Solution (NIS)

$$
\begin{gathered}
A^{+}=\left\{V_{1}^{+}, \ldots, V_{n}^{+}\right\}=\left\{\left(\operatorname{maxj} V_{i j} \mid i \in I\right),\left(\operatorname{minj} V_{i j} \mid i \in J\right)\right\} \\
A^{-}=\left\{V_{1}^{-}, \ldots, V_{n}^{-}\right\}=\left\{\left(\operatorname{minj} V_{i j} \mid i \in I\right),\left(\operatorname{maxj} V_{i j} \mid i \in J\right)\right\},
\end{gathered}
$$

where I represents the benefit criteria and J represents the cost criteria.

\section{e. Separation Measure Calculation}

In this step, the conditions of the criteria are to be compared with that of the ideal (positive and negative). In order to determine the distance of the alternatives from the ideal solution, the following equation is used:

$$
d_{i}^{+}=\sqrt{\sum_{j=1}^{n}\left(V_{i j}-V_{j}^{+}\right)^{2}}, i=1, \ldots, m
$$

And in order to determine the distance of the alternatives from the worst solution the following equation is used:

$$
d_{\mathrm{i}}=\sqrt{\sum_{\mathrm{j}=1}^{\mathrm{n}}\left(\mathrm{V}_{\mathrm{ij}}-\mathrm{V}_{\mathrm{j}}^{-}\right)^{2}}, i=1, \ldots, m,
$$

f. Determining the Final Scores of the Choices Based on Approximation to the best Solution and Distance from the worst Solution

In this step, the final weight of the choices is calculated based on the results of the previous steps as follows:

$$
C_{i}=\frac{d_{i}^{-}}{\left(d_{i}^{+}+d_{i}^{-}\right)}
$$

where $i=1, \ldots, m$

Subsequent to calculating the weights of the choices, it will be possible to rank them based on the scores they have gained to possess and finally make the necessary decisions for the problem at hand. 


\section{Evaluating Six Routes of the Public Bus Network of Shiraz}

Shiraz, as the capital of Fars province and the cultural capital of Iran, with a population of 1.28 million (based on the census carried out in 2006), is among the largest metropolitans of Iran. Shiraz is well-known as the cradle of the Persian Civilization and its history dates back to 4,000 years ago. According to an official survey, the shares of the different modes of travel in this city are as follows: private cars and taxis with 60 percent, buses with 30 percent and the other modes such as walking and cycling with 10 percent which is an unsustainable trend in a longer term. Therefore, the public bus is the main mode of public transportation (Soltani and Sharifi, 2012). For the time being, public transportation in Shiraz relies mainly on the bus network and the subway system is not opened yet. The metropolitan area consists of 9 Zones each of which has its own municipal authority. The data on the number of bus lines in Shiraz were obtained from Shiraz Organization of Public Bus (SOPB), Municipality of Metropolitan Shiraz, with some modifications made by the authors. For 71 routes with origin to destination run and reverse, the average route length is $11.041 \mathrm{~km}$. Among these 142 routes, the shortest one has a length of $4.142 \mathrm{~km}$ and the longest is $41.446 \mathrm{~km}$. The number of stops per $\mathrm{km}$ route is 1.16 .

For the present study, among the existing 71 routes in the bus network of Shiraz, 6 routes (Figure 2) were chosen as the sample. These 6 routes were the densest of the system. On the other hand, the computations of more routes would be very complicated and less useful. The goal of the paper was introducing a new methodology in bus route evaluation (BRE) literature rather than the evaluation of whole system.

After seeking expert opinions, in the first stage, the weights of the criteria and the indices considered for bus route evaluation were determined in the Fuzzy AHP model. The reason for using Fuzzy numbers in the pair-wise comparisons in this stage is including the vagueness of the expert opinions when giving weight to criteria and indices. Details are provided in Tables 1 to 5 . 


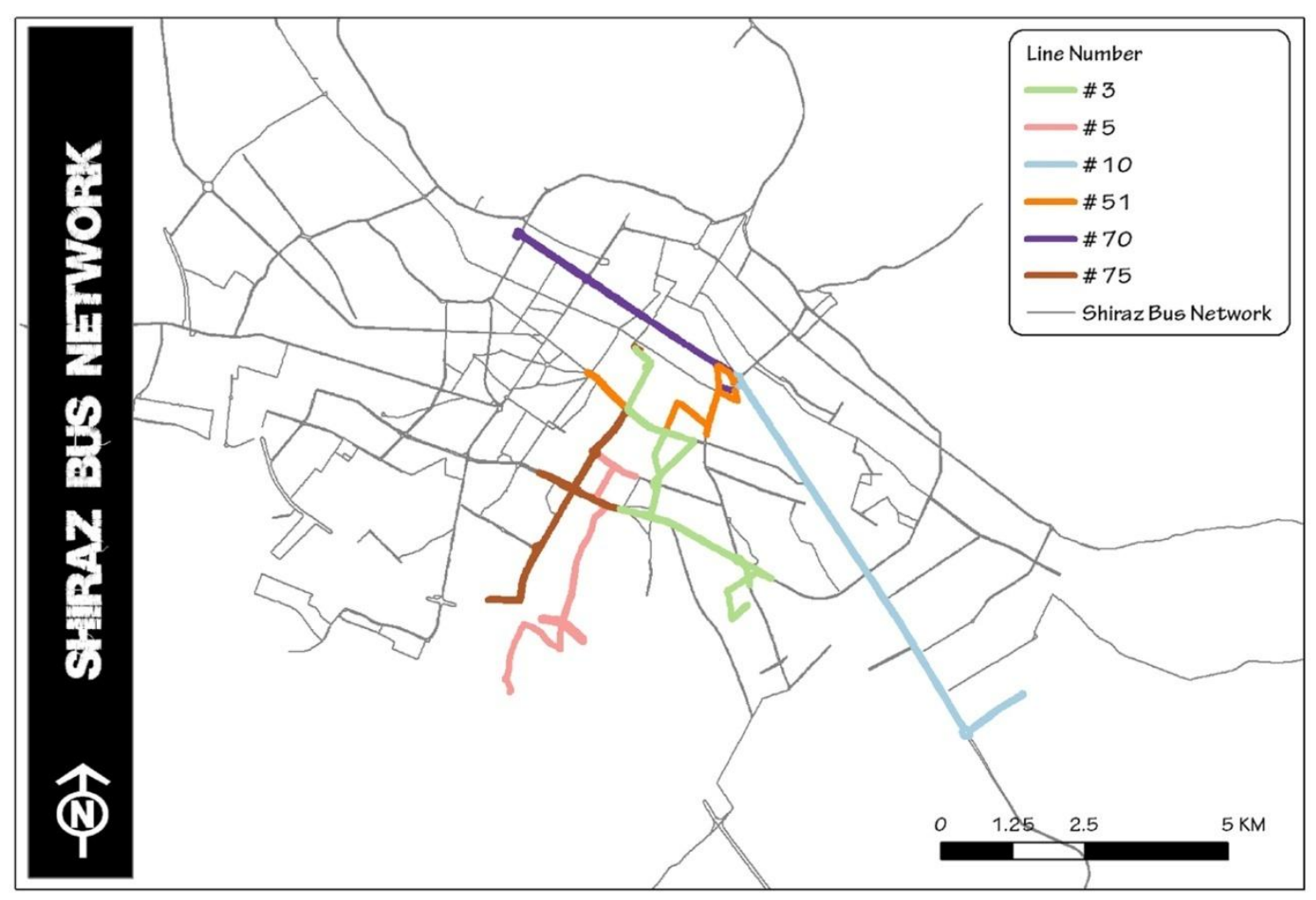

Figure 2- The selected bus routes of Shiraz bus network

Table 1 - Fuzzy AHP scales

\begin{tabular}{ccc}
\hline Inverse Scales & Fuzzy Scales & Linguistic Scales \\
\hline$(1,1,1)$ & $(1,1,1)$ & Equally Preferred \\
$(1 / 4,1 / 3,1 / 2)$ & $(2,3,4)$ & Moderately Preferred \\
$(1 / 6,1 / 5,1 / 4)$ & $(4,5,6)$ & Strongly Preferred \\
$(1 / 8,1 / 7,1 / 6)$ & $(6,7,8)$ & Very Strongly Preferred \\
$(1 / 9,1 / 9,1 / 9)$ & $(9,9,9)$ & Absolutely Preferred \\
\hline
\end{tabular}


Table 2 - Criteria weights obtained from the Fuzzy AHP model

\begin{tabular}{|c|c|c|c|c|c|}
\hline $\begin{array}{c}\text { Design } \\
\text { sub-criteria }\end{array}$ & RD & SD & EP & PC & Weight \\
\hline RD & $(1,1,1)$ & $(1 / 3,1 / 2,1)$ & $(1,1,1)$ & $(1,2,3)$ & 0.1465 \\
\hline SD & $(1,2,3)$ & $(1,1,1)$ & $(1,2,3)$ & $(2,3,4)$ & 0.1465 \\
\hline EP & $(1,1,1)$ & $(1 / 3,1 / 2,1)$ & $(1,1,1)$ & $(1,2,3)$ & 0.4632 \\
\hline $\mathbf{P C}$ & $(1 / 3,1 / 2,1)$ & $(1 / 4,1 / 3,1 / 2)$ & $(1 / 3,1 / 2,1)$ & $(1,1,1)$ & 0.1465 \\
\hline \multicolumn{3}{|c|}{$\lambda_{\max }=4.0102$} & \multicolumn{3}{|c|}{$\mathrm{RI}=0.9$} \\
\hline \multicolumn{3}{|c|}{$\mathrm{CI}=0.003$} & \multicolumn{3}{|c|}{$\mathrm{CR}=0.004$} \\
\hline
\end{tabular}

Table 3 - The weights of the sub-criteria of route design

\begin{tabular}{|c|c|c|c|c|c|c|}
\hline $\begin{array}{c}\text { Design } \\
\text { sub-criteria }\end{array}$ & PD & ED & RD & RO & $\mathrm{NC}$ & Weight \\
\hline PD & $(1,1,1)$ & $(1,1,1)$ & $(1 / 4,1 / 3,1 / 2)$ & $(1,1,1)$ & $(1,2,3)$ & 0.1465 \\
\hline ED & $(1,1,1)$ & $(1,1,1)$ & $(1 / 4,1 / 3,1 / 2)$ & $(1,1,1)$ & $(1,2,3)$ & 0.1465 \\
\hline RD & $(2,3,4)$ & $(2,3,4)$ & $(1,1,1)$ & $(2,3,4)$ & $(4,5,6)$ & 0.4632 \\
\hline RO & $(1,1,1)$ & $(1,1,1)$ & $(1 / 4,1 / 3,1 / 2)$ & $(1,1,1)$ & $(1,2,3)$ & 0.1465 \\
\hline NC & $(1 / 3,1 / 2,1)$ & $(1 / 3,1 / 2,1)$ & $(1 / 6,1 / 5,1 / 4)$ & $(1 / 3,1 / 2,1)$ & $(1,1,1)$ & 0.0974 \\
\hline \multicolumn{3}{|c|}{$\lambda \max =5.004$} & \multicolumn{4}{|c|}{$\mathrm{RI}=1.120$} \\
\hline \multicolumn{3}{|c|}{$\mathrm{CI}=0.010$} & \multicolumn{4}{|c|}{$\mathrm{CR}=0.009$} \\
\hline
\end{tabular}


Table 4 - Weights of the scheduling sub-criteria

\begin{tabular}{|c|c|c|c|c|c|c|}
\hline $\begin{array}{l}\text { Scheduling } \\
\text { sub-criteria }\end{array}$ & HE & DE & DST & S_vs_NS & NEF & weight \\
\hline HE & $(1,1,1)$ & $(1,1,1)$ & $(1,2,3)$ & $(2,3,4)$ & $(1,1,1)$ & 0.2478 \\
\hline DE & $(1,1,1)$ & $(1,1,1)$ & $(1,2,3)$ & $(2,3,4)$ & $(1,1,1)$ & 0.2478 \\
\hline DST & $(1 / 3,1 / 2,1)$ & $(1 / 3,1 / 2,1)$ & $(1,1,1)$ & $(1,2,3)$ & $(1 / 3,1 / 2,1)$ & 0.1841 \\
\hline S-vs-NS & $(1 / 4,1 / 3,1 / 2)$ & $(1 / 4,1 / 3,1 / 2)$ & $(1 / 3,1 / 2,1)$ & $(1,1,1)$ & $(1 / 4,1 / 3,1 / 2)$ & 0.0726 \\
\hline NEF & $(1,1,1)$ & $(1,1,1)$ & $(1,2,3)$ & $(2,3,4)$ & $(1,1,1)$ & 0.2478 \\
\hline \multicolumn{3}{|c|}{$\lambda \max =5.004$} & \multicolumn{4}{|c|}{$\mathrm{RI}=1.121$} \\
\hline \multicolumn{3}{|c|}{$\mathrm{CI}=0.002$} & \multicolumn{4}{|c|}{$\mathrm{CR}=0.002$} \\
\hline
\end{tabular}

Table 5 - Weights of the economic sub-criteria

\begin{tabular}{cccc}
\hline Sub-criteria & KUR & PPK & weight \\
\hline KUR & $(1,1,1)$ & $(1 / 4,1 / 3,1 / 2)$ & 0.177 \\
PPK & $(2,3,4)$ & $(1,1,1)$ & 0.823 \\
\hline
\end{tabular}


Table 6 - Weights of the passenger comfort sub-criteria

\begin{tabular}{|c|c|c|c|c|c|}
\hline $\begin{array}{c}\text { Passenger comfort } \\
\text { sub-criteria }\end{array}$ & OS & OLD & DSB & STU & weight \\
\hline OS & $(1,1,1)$ & $(4,5,6)$ & $(4,5,6)$ & $(2,3,4)$ & 0.5417 \\
\hline OLD $(65 Y)$ & $(1 / 6,1 / 5,1 / 4)$ & $(1,1,1)$ & $(1,1,1)$ & $(1 / 3,1 / 2,1)$ & 0.0856 \\
\hline DSB & $(1 / 6,1 / 5,1 / 4)$ & $(1,1,1)$ & $(1,1,1)$ & $(1 / 3,1 / 2,1)$ & 0.0856 \\
\hline STU & $(1 / 4,1 / 3,1 / 2)$ & $(1,2,3)$ & $(1,2,3)$ & $(1,1,1)$ & 0.2891 \\
\hline \multicolumn{3}{|c|}{$\lambda \max =4.004$} & \multicolumn{3}{|c|}{$\mathrm{RI}=0.901$} \\
\hline \multicolumn{3}{|c|}{$\mathrm{CI}=0.001$} & \multicolumn{3}{|c|}{$\mathrm{CR}=0.001$} \\
\hline
\end{tabular}

At the second stage, subsequent to determining the weights of the criteria and indices using spatial and statistical analysis, the final weight of the routes was calculated using the TOPSIS method. The values for indices were calculated and entered in the decision making table (Table 6) using the explanations given in part 2 and considering the statistical data gathered in the beginning, the middle, and the weekend and also considering the existing data from the transportation network, bus routes, and census blocks for the 6 routes under evaluation. After normalizing the decision table (Table 7), the obtained weights from the Fuzzy AHP stage were applied in the normalized matrix (Table 8) and subsequent to determining the best and worst solutions vectors (Table 9) and calculating the distance, the final score for the routes and their ranks were achieved (Table 10). Considering the obtained results, routes 51 and 75 have are in good situation of performance and efficiency and lines 5 and 10 are in need of review for the purpose of improvements. 
Table 7 - Step 1: Decision Table

\begin{tabular}{|c|c|c|c|c|c|c|c|c|c|c|c|c|c|c|c|c|}
\hline \multirow{2}{*}{$\begin{array}{c}\text { Criteria } \\
\text { Index }\end{array}$} & \multicolumn{5}{|c|}{ Route Design } & \multicolumn{5}{|c|}{ Schedule Design } & \multicolumn{2}{|c|}{ Economic } & \multicolumn{4}{|c|}{ Safety \& Comfort } \\
\hline & PD & ED & RDF & RO & NC & HE & $\mathbf{D E}$ & DST & S_VS_NS & NEF & KUR & PPK & OS & STU & $65 Y$ & Dis \\
\hline Weight & 0.032 & 0.032 & 0.102 & 0.032 & 0.021 & 0.109 & 0.109 & 0.081 & 0.032 & 0.109 & 0.039 & 0.181 & 0.064 & 0.010 & 0.010 & 0.034 \\
\hline \multicolumn{17}{|l|}{ Line $\mathbf{N}$. } \\
\hline 3 & 193.301 & 52.247 & 1.312 & 4.119 & 1.882 & 1.871 & 5.443 & 0.050 & 3.191 & 19.019 & 0.950 & 105.958 & 15.387 & 34.814 & 9.653 & 3.784 \\
\hline 5 & 154.467 & 44.798 & 1.217 & 2.358 & 1.585 & 2.562 & 5.830 & 0.053 & 3.988 & 32.994 & 0.923 & 89.773 & 13.911 & 29.305 & 7.384 & 2.498 \\
\hline 10 & 134.866 & 41.754 & 1.148 & 1.236 & 1.341 & 1.028 & 3.143 & 0.209 & 12.217 & 22.567 & 0.997 & 132.694 & 16.958 & 24.407 & 5.778 & 1.754 \\
\hline 51 & 210.094 & 59.755 & 1.326 & 5.869 & 5.647 & 1.137 & 3.143 & 0.000 & 0.000 & 11.730 & 0.989 & 222.354 & 14.190 & 33.878 & 15.292 & 4.540 \\
\hline 70 & 124.782 & 36.409 & 1.000 & 5.157 & 5.105 & 1.365 & 5.553 & 0.103 & 5.500 & 20.213 & 0.997 & 224.629 & 13.561 & 24.191 & 9.176 & 1.966 \\
\hline 75 & 168.347 & 51.682 & 1.137 & 3.881 & 2.135 & 1.355 & 2.979 & 0.000 & 0.000 & 7.295 & 0.907 & 124.852 & 18.324 & 29.113 & 8.276 & 2.692 \\
\hline
\end{tabular}

Table 8 - Step 2: Normalized Decision Table

\begin{tabular}{|c|c|c|c|c|c|c|c|c|c|c|c|c|c|c|c|c|}
\hline \multirow{2}{*}{$\begin{array}{c}\text { Criteria } \\
\text { Index }\end{array}$} & \multicolumn{5}{|c|}{ Route Design } & \multicolumn{5}{|c|}{ Schedule Design } & \multicolumn{2}{|c|}{ Economic } & \multicolumn{4}{|c|}{ Safety $\&$ Comfort } \\
\hline & PD & ED & RDF & RO & $\mathrm{NC}$ & HE & DE & DST & S_VS_NS & NEF & KUR & PPK & OS & STU & $65 Y$ & Dis \\
\hline Weight & 0.032 & 0.032 & 0.102 & 0.032 & 0.021 & 0.110 & 0.110 & 0.081 & 0.032 & 0.110 & 0.039 & 0.181 & 0.064 & 0.010 & 0.010 & 0.034 \\
\hline \multicolumn{17}{|l|}{ Line $\mathbf{N}$. } \\
\hline 3 & 0.472 & 0.441 & 0.448 & 0.412 & 0.224 & 0.466 & 0.491 & 0.203 & 0.223 & 0.376 & 0.404 & 0.271 & 0.406 & 0.481 & 0.405 & 0.509 \\
\hline 5 & 0.378 & 0.378 & 0.416 & 0.236 & 0.189 & 0.638 & 0.526 & 0.219 & 0.278 & 0.652 & 0.392 & 0.230 & 0.367 & 0.405 & 0.310 & 0.336 \\
\hline 10 & 0.330 & 0.352 & 0.392 & 0.124 & 0.160 & 0.256 & 0.283 & 0.856 & 0.852 & 0.446 & 0.424 & 0.340 & 0.447 & 0.337 & 0.243 & 0.236 \\
\hline 51 & 0.513 & 0.504 & 0.453 & 0.586 & 0.673 & 0.283 & 0.283 & 0.000 & 0.000 & 0.232 & 0.420 & 0.570 & 0.374 & 0.468 & 0.642 & 0.610 \\
\hline 70 & 0.305 & 0.307 & 0.342 & 0.515 & 0.609 & 0.340 & 0.501 & 0.423 & 0.384 & 0.400 & 0.423 & 0.575 & 0.358 & 0.334 & 0.385 & 0.264 \\
\hline 75 & 0.411 & 0.436 & 0.388 & 0.388 & 0.255 & 0.338 & 0.269 & 0.000 & 0.000 & 0.144 & 0.385 & 0.320 & 0.483 & 0.402 & 0.347 & 0.362 \\
\hline
\end{tabular}


Table 9 - Step 3: Weighted Decision Table

\begin{tabular}{|c|c|c|c|c|c|c|c|c|c|c|c|c|c|c|c|c|}
\hline \multirow{2}{*}{$\begin{array}{c}\text { Criteria } \\
\text { Index }\end{array}$} & \multicolumn{5}{|c|}{ Route Design } & \multicolumn{5}{|c|}{ Schedule Design } & \multicolumn{2}{|c|}{ Economic } & \multicolumn{4}{|c|}{ Safety \& Comfort } \\
\hline & PD & ED & RDF & RO & $\mathrm{NC}$ & HE & DE & DST & S_VS_NS & NEF & KUR & PPK & OS & STU & $65 \mathrm{Y}$ & Dis \\
\hline Weight & 0.032 & 0.032 & 0.102 & 0.032 & 0.021 & 0.110 & 0.110 & 0.081 & 0.032 & 0.110 & 0.039 & 0.181 & 0.064 & 0.010 & 0.010 & 0.034 \\
\hline \multicolumn{17}{|l|}{ Line $\mathbf{N}$. } \\
\hline 3 & 0.015 & 0.014 & 0.046 & 0.013 & 0.005 & 0.051 & 0.054 & 0.017 & 0.007 & 0.041 & 0.016 & 0.049 & 0.026 & 0.005 & 0.004 & 0.018 \\
\hline 5 & 0.012 & 0.012 & 0.042 & 0.008 & 0.004 & 0.070 & 0.058 & 0.018 & 0.009 & 0.072 & 0.015 & 0.042 & 0.024 & 0.004 & 0.003 & 0.012 \\
\hline 10 & 0.011 & 0.011 & 0.040 & 0.004 & 0.003 & 0.028 & 0.031 & 0.070 & 0.027 & 0.049 & 0.017 & 0.061 & 0.029 & 0.003 & 0.003 & 0.008 \\
\hline 51 & 0.017 & 0.016 & 0.046 & 0.019 & 0.014 & 0.031 & 0.031 & 0.000 & 0.000 & 0.025 & 0.016 & 0.103 & 0.024 & 0.005 & 0.007 & 0.021 \\
\hline 70 & 0.010 & 0.010 & 0.035 & 0.017 & 0.013 & 0.037 & 0.055 & 0.034 & 0.012 & 0.044 & 0.017 & 0.104 & 0.023 & 0.003 & 0.004 & 0.009 \\
\hline 75 & 0.013 & 0.014 & 0.040 & 0.013 & 0.005 & 0.037 & 0.029 & 0.000 & 0.000 & 0.016 & 0.015 & 0.058 & 0.031 & 0.004 & 0.004 & 0.012 \\
\hline
\end{tabular}

Table 10 - Step 4: Positive Ideal Solution (PIS) and Negative Ideal Solution (NIS)

\begin{tabular}{ccccccccccccccccc}
\hline Index & PD & ED & RDF & RO & NC & HE & DE & DST & S_VS_NS & NEF & KUR & PPK & OS & STU & 65Y & Dis \\
\hline A+ & 0.017 & 0.016 & 0.035 & 0.004 & 0.014 & 0.028 & 0.029 & 0.000 & 0.000 & 0.016 & 0.017 & 0.104 & 0.031 & 0.005 & 0.007 & 0.021 \\
A- & 0.010 & 0.010 & 0.046 & 0.019 & 0.003 & 0.070 & 0.058 & 0.070 & 0.027 & 0.072 & 0.015 & 0.042 & 0.023 & 0.003 & 0.003 & 0.008 \\
\hline
\end{tabular}

Table 11 - Step 5: Separation Measure Calculation, Final Scores Calculation and Ranking

\begin{tabular}{cccccc}
\hline Line No. & $\mathbf{d}_{\mathbf{i}}^{+}$ & $\mathbf{d}_{\mathbf{i}}^{-}$ & $\mathbf{C}_{\mathbf{i}}$ & Normalized Score & Rank \\
\hline 3 & 0.0738 & 0.0691 & 0.4834 & 0.1442 & 4 \\
5 & 0.1015 & 0.0566 & 0.3579 & 0.1068 & 6 \\
10 & 0.0944 & 0.0606 & 0.391 & 0.1166 & 5 \\
51 & 0.0225 & 0.1188 & 0.841 & 0.2509 & 1 \\
70 & 0.0576 & 0.0863 & 0.5999 & 0.179 & 3 \\
75 & 0.0498 & 0.1052 & 0.6785 & 0.2024 & 2 \\
\hline
\end{tabular}




\section{Conclusion}

In this study, an operational framework for bus route network evaluation was developed. The first stage in this process included determining the criteria and indices for evaluation and was carried out by studying theoretical texts and analyzing the factors affecting the performance of the routes and also the data extracted from the analysis of the collected data. A number of potential useful for route evaluation were excluded from the evaluation framework since they shared a similarity in all bus routes or because the required data could not be provided.

In the next stage, the weights of the evaluation criteria were determined using expert opinions and the Fuzzy AHP method. The advantage of using this method for giving weight to the criteria was its simplicity and flexibility and also its ability to spot the vagueness of the expert opinions in the Fuzzy environment. After calculating the quantitative weights of the evaluation indices, the final scores of the routes were achieved through the use of the TOPSIS method. the vagueness of the expert opinions in the Fuzzy environment.

The considerable advantages of using the two-stage evaluation method in this study are as follows:

a) The calculations are simple and the evaluating model is cost-effective.

b) Using the hierarchical construction of the Fuzzy AHP method for giving weight to the criteria makes up for the weakness of the TOPSIS method in lacking a logical process for the comparative weighting of the evaluation criteria and at the same time considers the uncertainty of the expert opinions using Fuzzy numbers and, therefore, creates a more robust evaluation construction.

c) Due to the fact that all of the criteria under analysis are quantitative ones, using the TOPSIS method induces utilization of the exact quantities in model without causing any data loss and at the same time it would be possible to use qualitative criteria if needed.

d) For evaluation of all bus routes, due to the high number of choices, most of the multiplecriteria evaluation methods would be rendered inefficient since the calculations would be complicated and massive, while the number of choices in the TOPSIS method does not affect the amount of calculations. 
This study suffers from some limitations and further research should pay more attention on them: choosing only six lines out of 71 routes, applying more precise way to choosing the sampled routes; using simplified regular indices for measuring the efficiency of bus routes; and not observing subjective measures of service quality on the basis of users' perception about the service and measurements provided by the transit agency are among the shortages of this study.

In order to examine the impressibility of the scores by criteria weights, sensitivity analysis can be used which is not employed in the present study due to the high number of relocations and the time and effort consuming calculations. Finally, as suggestions for further research, topics such as testing the feasibility of the use of other hybrid models in order to make up for the weaknesses of this study and creating the possibility to compare the results, creating bus route evaluation software to be used by the respective organizations, and also creating automated systems for extracting the evaluation data for the purpose of period or constant update can be mentioned.

In conclusion, public bus service can play significant role in developing countries and provide various benefits, including direct benefits to users and indirect benefits to the society. This study attempted to evaluate the efficiency of system through investigating different aspects of bus routes. It explains how to create a scientific evaluation framework basing on multi-criteria techniques that incorporates various aspects of the system. It discusses how to rank particular public bus routes in terms of technical, economical and social characteristics. This framework can be developed for evaluating other public and semi-public systems of transportation such as taxis and trains. 


\section{References}

Awasthi, A., Chauhan, S.S., Omrani, H. (2011a), Application of fuzzy TOPSIS in evaluating sustainable transportation systems, Expert systems with Applications 38, 12270-12280

Awasthi, A., Chauhan, S.S., Omrani, H. and Panahi, A. (2011b) "A hybrid approach based on SERVQUAL and fuzzy TOPSIS for evaluating transportation service quality", Computers \& Industrial Engineering, vol. 61; n. 3, 637-646.

Ayag, Z., Ozdemir, R.G. (2006), A fuzzy AHP approach to evaluating machine tool alternatives, journal of Intelligent manufacturing 17, 179-190.

Badri, M.A. (2001), A Combined AHP-GP model for quality control systems, in: International Journal of Production economics, 72, 24-40.

Chen, X., Yu, L. Zhang, Y., Guo, J. (2009), Analyzing urban bus service reliability at the stop, route and network levels, Transportation Research Part A43, 722-734.

Eichler, M., Daganzo, C.F. (2006), Bus Lanes with intermittent priority: Strategy formulae and an evaluation, Transportation Research Part B40, 731-744.

Gumus, A.T. (2009), Evaluation of Hazardous waste transportation firms by using a two step fuzzy AHP and TOPSIS methodology, Expert Systems with Application 36, 4067-4074.

Huang, A., Shen, J. \& Guan, W. (2007), Study on Bus Route Evaluation System in Beijing bases on AHP, In: Proceedings of the 2007 IEEE, Intelligent transportation Systems Conference, Seattle, WA, USA., 419-424.

Hwang, C.L., Yoon, K. (1981), Multiple Attribute Decision Making: Methods and Applications, Heidelberg: Springer-Verlag, New York

Lao, Y., Liu, L. (2009), Performance evaluation of bus lines with data envelopment analysis and geographic information systems, Computers, Environment and Urban Systems 33, no. 4, 247 255 .

Mahmoodzadeh, S., Shahrabi, M., Pariazar, J., and Zaeri, M.S. (2007), Project selection by using fuzzy AHP and TOPSIS technique, World Academy of Science,Engineering and Technology, 30, 333-338.

Mergias, I., Moustakus, K., Papadopoulos, A., \& Loizidiou, M. (2007), Multicriteria decision aid approach for the selection of the best compromise management scheme for ELVs: the case of Cyprus Journal of Hazardous Materials, 147, 706-717

Oort, N., Nes, R. (2003), Service regularity analysis for urban transit network design, In: Proceedings of the 82nd Annual meeting of the transportation Research Board, Washington, D.C.

Opricovic, S. and Tzeng, G. H. (2004), Comprise solution by MCDM methods: A comparative analysis of VIKOR and TOPSIS, European Journal of Operational Research, vol. 156, 445-455.

Sheth, C., Triantis, K., Teodorovic, D. (2007), Performance evaluation of bus routes: A Provider and Passenger Perspective, Transportation Research Part E43,453-478.

Soltani, A. and Sharifi, E. (2012), A Case Study of Sustainable Urban Planning Principles in Curitiba (Brazil) and Their Applicability in Shiraz (Iran), International Journal of Development and Sustainability, vol. 1 no. 2 (In Press).

Soltani, A. and Zargari, E. M. (2011), Hospital site selection using two-stage fuzzy multi-criteria decision making process, Journal of Urban and Environmental Engineering, 5 (1), 32-43. 
The Federal Transit Administration (FTA). (1995), Bus Route Evaluation Standards, A Synthesis of Transit in Public Transportation, National Academy Press, Washington, D.C.

Tomazinis, A.R. (1975), Productivity, Efficiency and Quality in Urban Transportation Systems, Lexington Books, Lexington, MA.

Tzeng, G.H., Lin, C.W., Opricovic, S. (2005), Multicriteria analysis of alternative-fuel buses for public transportation, Energy Policy 33, 1373-1383.

Vahdani, B., Mousavi, S.M., Tavakkoli Moghaddam, R. (2011), Group decision making based on novel fuzzy modified TOPSIS method, Applied Mathematical Modelling 35, 4257-4269.

Wall, G. \& McDonald, M. (2007), Improving bus service quality and information in Winchester, Transportation Policy 14, 165-179

Wang, Y.M. \& Elhag, T.M.S. (2006), Fuzzy TOPSIS method based on alpha level sets with an application to bridge risk assessment, in. Expert systems with Applications, 31, 309-315.

Wirasinghe, S.C., Vandebona, U. (2011), Route Layout analysis for express buses, Transportation Research Part C 19, 374-385.

Yu, C.S. (2002), A GP-AHP method for solving group decision-making fuzzy AHP Problems, Computer and Operations Research 29, 1969-2001.

Yue, Z. (2011), A method for group decision-making based on determining weights of decision makers using TOPSIS model, Applied Mathematical Modeling, 35, 1926-1936

Zhou, Y., Thill, J., Huang, Z. (2011), Design of a user centric decision support tool for fixed-route bus travel planning, Applied Geography 31, 1173-1184. 